\title{
Current Guidelines and Future Strategies for the Management of Cow's Milk Allergy
}

\author{
Yvan Vandenplas (1D' \\ Helen A Brough ${ }^{2-4}$ \\ Alessandro Fiocchi ${ }^{5}$ \\ Mohamad Miqdady ${ }^{6}$ \\ Zakiudin Munasir $^{7}$ \\ Silvia Salvatore ${ }^{8}$ \\ Nikhil Thapar ${ }^{9}$ \\ Carina Venter ${ }^{10}$ \\ Mario C Vieira (D) $^{\prime \prime}$ \\ Rosan Meyer ${ }^{12,13}$
}

'Vrije Universiteit Brussel (VUB), UZ Brussel, KidZ Health Castle, Brussels, Belgium;

${ }^{2}$ Department Women and Children's Health (Pediatric Allergy), School of Life Course

Sciences, Faculty of Life Sciences and Medicine,

King's College London, London, UK; ${ }^{3}$ Peter

Gorer Department of Immunobiology, School

of Immunology and Microbial Sciences, King's

College London, London, UK; ${ }^{4}$ Children's

Allergy Service, Evelina Children's Hospital,

Guy's and St. Thomas's NHS Foundation Trust,

London, UK; ${ }^{5}$ Translational Research in

Pediatric Specialities Area, Division of Allergy,

Bambino Gesù Children's Hospital, IRCCS,

Piazza Sant'Onofrio, Rome, Italy; ${ }^{6}$ Department

of Pediatrics, Sheikh Khalifa Medical City,

College of Medicine \& Health Sciences, Khalifa

University, Khalifa, United Arab Emirates;

${ }^{7}$ Department of Child Health,

Ciptomangunkusumo Hospital-Medical Faculty

Universitas Indonesia, Jakarta, Indonesia;

${ }^{8}$ Pediatric Department, Hospital "F. Del Ponte",

University of Insubria, Varese, Italy;

${ }^{9}$ Gastroenterology, Hepatology and Liver

Transplant, Queensland Children's Hospital,

Brisbane, Queensland, Australia; ${ }^{10}$ University of

Colorado, Children's Hospital Colorado,

Denver, CO, USA; "'Center for Pediatric

Gastroenterology -Hospital Pequeno Príncipe,

Curitiba, Brazil; ${ }^{12}$ Department of Paediatrics,

Imperial College, London, UK; ${ }^{13}$ Department

Nutrition and Dietetics, University of

Winchester, Winchester, UK

Correspondence: Yvan Vandenplas Vrije Universiteit Brussel (VUB), UZ Brussel, KidZ Health Castle, Brussels, Belgium

Email Yvan.vandenplas@uzbrussel.be

\begin{abstract}
Exclusive breast feeding is recommended in all guidelines as the first choice feeding. Cow milk allergy (CMA) can be diagnosed by a diagnostic elimination diet for 2 to 4 weeks with a hypo-allergenic formula, followed by a challenge test with intact cow milk protein. The most often used hypo-allergenic formula for the diagnostic elimination diet and the therapeutic diet is a CM based extensive hydrolysate. CM-based partial hydrolysates cannot be recommended in the management of CMA because of insufficient efficacy and possible reactions, but about half of the infants with CMA may tolerate a partial hydrolysate. The pros and cons of other dietary options are discussed in this paper. The use of an amino acid-based formula and/or rice based hydrolysate formula during the diagnostic elimination and therapeutic diet is debated. When available, there is sufficient evidence to consider rice hydrolysates as an adequate alternative to CM-based hydrolysates, since some infants will still react to the CM hydrolysate. The pros and cons of dietary options such as soy formula, buckwheat, almond, pea or other plant based dietary products are discussed. Although the majority of the plant-based beverages are nutritionally inadequate, some are nutritionally adapted for toddlers. However, accessibility and content vary by country and, thus far there is insufficient evidence on the efficacy and tolerance of these plant-based drinks (except for soy formula and rice hydrolysates) to provide an opinion on them.

Conclusion: A diagnostic elimination diet, followed by a challenge remains the diagnostic standard. The use of an awareness tool may result in a decrease of delayed diagnosis. Breastmilk remains the ideal source of nutrition and when not available a CM extensively hydrolyzed formula, rice hydrolysate or amino acid formula should be recommended. More evidence is needed regarding plant-based drinks.
\end{abstract}

Keywords: amino acid formula, challenge test, cow milk allergy, hydrolysate, plant-based drink, rice hydrolysate, soy formula

\section{Introduction}

Cow's milk allergy (CMA) is the most common food allergy in infancy, with a reported prevalence of between 0.54 and $4.9 \%$, varying by region and type of feeding (human milk vs formula feeding). ${ }^{1,2}$ IgE-mediated reactions typically occur immediately after ingestion whereas non- $\operatorname{IgE}$ mediated are delayed and take up to 48 hours to develop, but still involve the immune system. IgE mediated symptoms involve the skin, respiratory and gastro-intestinal (GI) tract, as well as general manifestations. While the immediate symptoms of immunoglobulin $\mathrm{E}$ (IgE) mediated CMA are readily recognized, the diagnosis of non-IgE mediated CMA can pose a challenge due to the delayed onset of symptoms and overlap with other common pediatric manifestations of functional gastrointestinal disorders such as 
infantile colic, gastro-esophageal reflux (disease) or even infections. $^{3-5}$ However, an appropriate timely diagnosis and management of CMA is of paramount importance, particularly during the critical early years of growth and development. Several studies have suggested that, compared to healthy children, growth in children with food allergy is often impaired and vitamin and mineral deficiencies are common. ${ }^{6-10}$ Causative factors include prolonged dietary restrictions as part of single or multiple allergen avoidance, associated feeding difficulties and atopic comorbidities, rather than differences in energy expenditure or nutritional needs. ${ }^{6,11}$ Infants and young children on an unsupervised cow's milk exclusion diet are at increased risk of micronutrient deficiencies, mainly relating to insufficient iron, iodine, calcium and vitamin D and B12 intake. $^{10-14}$ Additionally, the duration of a cow's milk exclusion diet worsens parents' perception of quality of life in children with food allergies. ${ }^{15}$ Data shows increased stress, worry, anxiety, and reduced health related quality of life and self-efficacy among caregivers of children with food protein induced enterocolitis syndrome. ${ }^{16}$

This paper aims to critical review existing guidelines for the management of CMA and speculate on upcoming possible adaptations and changes.

\section{Symptoms}

There is no symptom that is specific for CMA as its every manifestation can be caused by multiple conditions. Immediate IgE-mediated type symptoms include urticaria, lip swelling, facial angioedema, and at the severe end of the spectrum, anaphylaxis..$^{3-5}$ By contrast, non-IgE-mediated CMA may present with a wide range of gastrointestinal and systemic manifestations, including vomiting or regurgitation, diarrhea, rectal bleeding, feeding difficulties, and general symptoms such as persistent crying, sleep problems and failure to thrive. ${ }^{3-5,17}$ The spectrum of non-IgE mediated CMA includes proctocolitis, food protein induced enteropathy and enterocolitis syndrome and more recently eosinophilic esophagitis has also been recognized as a predominant non-IgE mediated condition with the most recent hypotheses proposing an IgG4 pathophysiology. ${ }^{18-21}$ Food Protein Induced Enterocolitis Syndrome is a non-IgE-mediated food allergy that typically presents in infancy, with repetitive protracted vomiting that begins approximately 1 to 4 hours after food ingestion. Vomiting is often accompanied by lethargy and pallor and can be followed by diarrhea. Delayed onset and absence of cutaneous and respiratory symptoms suggest a systemic reaction different from anaphylaxis.AA7 However, it is recognized that many subjects with eosinophilic esophagitis do also have positive IgE towards food or aero allergens. Conditions with mixed IgE- and non-IgE-mediated mechanisms such as atopic eczema, are also frequently associated with CMA. ${ }^{22,23}$ Chronic respiratory symptoms such as coughing, recurrent wheeze, rhinitis, can also be related to CMA. ${ }^{22-24}$ Although respiratory symptoms are part of the spectrum of symptoms of CMA, respiratory tract infections are, of course, a much more frequent etiology for these manifestations. The fact that children with CMA have a higher risk of developing respiratory tract infections complicates the understanding of the interactions between allergy and infection. ${ }^{24}$

\section{Diagnosis}

The diagnosis of an IgE mediated allergy is generally easier, because of the clear time-relation between ingestion of the offending food and the appearance of symptoms. In addition, specific IgE and skin prick tests contribute to the diagnosis of IgE mediated allergy in the right clinical setting. ${ }^{22,23}$ By contrast, non-IgE mediated and mixed CMA constitute a heterogeneous group of symptoms caused by immunological mechanisms that still need to be fully clarified. ${ }^{3,4,25}$ The diagnosis of the Food Protein Induced Enterocolitis Syndrome is primarily based on the clinical history of typical characteristic signs and symptoms with improvement after withdrawal of the suspected trigger food, after eliminating other potential causes. ${ }^{26}$ Oral food challenges help to confirm the diagnosis if the history is unclear and there is a favorable risk/benefit ratio. ${ }^{26} \mathrm{In}$ infants with persistent crying, esophageal and gastrointestinal motility parameters do not reliably differentiate non-IgE-mediated CMA from functional gastrointestinal disorders or gastro-esophageal reflux disease (GERD). ${ }^{27}$ In the group with non-IgE-mediated CMA, elimination of CMP significantly improved GER symptoms, esophageal peristaltic function, and mucosal integrity. ${ }^{27-29}$ The diagnosis in clinical practice, therefore, relies on an allergy focused history and physical examination, with the resolution of symptoms with the elimination of the presumed triggering allergens. ${ }^{27-29}$ Diagnostic confirmation is required with an oral food challenge (ideally blinded) and/or home reintroduction of the suspected food allergens after usually 2 to 4 weeks of elimination 
of cow's milk from the diet for IgE mediated symptoms and longer for non-IgE-mediated symptoms, even up to 6 weeks for eosinophilic esophagitis. ${ }^{27-29}$. The diagnosis of eosinophilic esophagitis requires upper gastrointestinal endoscopy and biopsies.

Several studies have investigated the diagnostic use of various fecal biomarkers, such as fecal calprotectin, $\alpha-1$ antitrypsin, $\beta$-defensin, tumor necrosis factor- $\alpha$, fecal IgA, eosinophil-derived neurotoxin and eosinophilic cationic protein, but none appear accurate in this condition. ${ }^{29}$ The measurement of food-specific IgG and IgG4 antibody levels also does not contribute towards diagnostic accuracy and the European Academy of Allergy and Clinical Immunology advises against using the latter tests for IgE mediated food allergies. ${ }^{29,30}$ The possible role for IgG4 in the pathophysiology of eosinophilic esophagitis, primarily a non-IgE mediated disease needs further clarification. ${ }^{19}$ The diagnostic contribution of the allergen-specific lymphocyte stimulation test needs to be further evaluated and is not available in routine clinical practice. ${ }^{29}$ The Atopy Patch Test has been proposed and appeared promising in non- $\operatorname{IgE}$ mediated allergy but has been insufficiently studied and standardized to be recommended by any of the official allergy bodies (including the National Institute of Allergy and Infectious Diseases (NIAID) and European Academy for Allergy and Clinical Immunology (EAACI) guidelines). Other possible diagnostic tests such as intestinal vessel density, the basophil activation test, and genetics are not routinely available and need further evaluation. ${ }^{29} \mathrm{~A}$ clinical awareness score, the Cow's Milk related Symptom Score (CoMiSS ${ }^{\text {TM}}$ ) was recently developed. ${ }^{31}$ Although further studies are needed to validate the CoMiSS in the diagnostic workup of CMA, it can already be considered a useful clinical awareness tool, especially for suspected non- $\operatorname{IgE}$ mediated CMA and to monitor the response to an elimination diet. ${ }^{29}$

An elimination diet and oral food challenge remains therefore the cornerstone for the diagnosis of CMA, although this test does not demonstrate the involvement of the immune system in the pathogenesis of the symptoms. Functional gastro-intestinal disorders associated with the intake of cow's milk will as well improve and relapse with an elimination diet and challenge. Today, our knowledge about the pathophysiologic mechanisms involved for both conditions is too limited to always clearly separate them.

\section{Management Options Breastfeeding and Extensively Hydrolyzed Formula in CMA}

The management of CMA relies on the strict dietary elimination of CMP from the infant's diet and, when applicable, also from the breastfeeding mother's diet. All guidelines on the management of CMA recommend continued breast feeding as the ideal nutrition for allergic infants. $^{22,26,32-35}$ In breastfed infants, with persistent symptoms, a 2-4 week maternal elimination diet is recommended but a re-introduction of CMP is crucial to confirm the diagnosis and to avoid an unnecessary and protracted diet that increases the nutritional risk for the mother. ${ }^{36}$ When breastmilk is not available or insufficient most guidelines advise an extensively hydrolyzed formula (EHF) as first choice formula for mild to moderate CMA, moving to AAF if EHF fails. ${ }^{22,23,27,32-35,37,38}$

Hypoallergenic formulas are tolerated, per definition, by $90 \%$ of subjects with CMA with a $95 \%$ confidence interval and are divided according to the degree of protein hydrolysis. EHFs contain short peptides (with the majority below $1500 \mathrm{Da}$ ) and amino acid formulas (AAF), provide protein in the form of simple amino acids. ${ }^{39,40}$ Studies have shown that between $2 \%$ and 18\% (average 10\%) of children with the immediate-type, IgE-mediated, CMA continue to react to an EHF. ${ }^{41-43}$ A Turkish economic driven study evaluated the rate of intolerance to EHF even as high as 29 to $40 \%$ which may reflect the severity of patients enrolled or the criteria used to define reactions. ${ }^{44}$ Allergy to EHF has to be considered in the presence of $\operatorname{IgE}$ mediated allergic manifestations such as anaphylaxis but also in case of non-IgE mediated chronic gastro-intestinal symptoms such as regurgitation, diarrhea and colic., ${ }^{3,45}$

A number of studies have demonstrated that EHFs provide adequate nutrition and normal growth in children with CMA. ${ }^{46-48}$ Growth was assessed in a randomized trial in healthy infants, enrolled between 0 and 9 days of life and followed up to 112 days of age. Infants fed AAF and a casein EHF showed similar results and not different from the ones obtained with a partial hydrolysate. ${ }^{49}$ Whether there is a different efficacy between whey or casein EHFs is still unclear. ${ }^{50}$ Normative data on the composition of Foods for Special Medical Purposes (FSMPs), including EHFs, have been updated and regulated in Europe (Commission Delegated Regulation (EU) 2016/128 of 25 September 2015 supplementing Regulation 
(EU) No 609/2013 of the European Parliament and of the Council as regards the specific compositional and information requirements for food for special medical purposes). Nevertheless, weight gain should be regularly checked particularly during the first two years of life.

Not all EHF are the same: since the type of protein (ie whey or casein) hydrolyzation technique differs between products, thus residual peptides are different, which further highlights the importance to only recommend EHF that have been tested clinically and shown to fulfill the AAP recommendations. ${ }^{51,52}$ Moreover, not all commercialized EHF products have undergone formal testing in the laboratory and clinical trials. ${ }^{51,52}$ Guidelines need to be developed for minimum technical and regulatory requirements for EHF products, including validated assays for ongoing quality control. ${ }^{52}$ Clinical trials assessing new EHF products for their hypo-allergenicity and ability to support normal growth remain the definitive proof of efficacy and safety in infants and young children with CMA. ${ }^{52,53}$

Apart from differences in ingredients, formulas also exhibit distinct differences in smell, texture, taste and aftertaste when compared to cow's milk formulas. ${ }^{54}$ Overall whey EHF, in particular those containing lactose, were judged to be of better palatability than casein EHF and AAFs. ${ }^{54}$ Amongst health care providers (HCPs) who manage infants with CMA, whey-based lactose-containing EHFs were ranked the most palatable. ${ }^{55}$ Taste preference studies are often done in adults and provide limited information regarding acceptability in pediatrics. Long-term intake of bitter- and sour-tasting EHFs and AAFs are reported to influence food preferences and food choice later in life. Infants fed EHF for 3 or 8 months, but not 1 month, showed greater acceptance of a savory broth relative to the plain broth and consumed it at a faster rate. ${ }^{56}$ In fact, consuming a substitute formula and/or a cow milk elimination diet in infancy has a long-term effect and has an impact the preference for bitter taste up to the age of 11 years. $^{57}$

In summary: only those EHF that have been clinically tested regarding both their hypo-allergenicity and supporting growth can be recommended, with a documented continuous quality control.

\section{Amino Acid-Based Formula}

Since no component of an AAF is derived from cow's milk, AAF are considered 100\% effective in treating CMA. Similar to EHFs, AAFs also have to comply with new EU regulations in regard to composition.
These formulas have also undergone growth studies and assessment on nutritional adequacy in children with CMA. ${ }^{58-63}$ According to most recommendations, indications for using AAF as first choice in infants with CMA include: anaphylaxis, symptoms not fully resolved on EHF, faltering growth/failure to thrive in particular with multiple food restrictions and if both skin and gastrointestinal tract are involved, eosinophilic esophagitis. ${ }^{2,32}$ In moderate forms of CMA the preference for EHF over $\mathrm{AAF}$ is cost driven and health care system or insurance reimbursement. The possible advantage of contact with cow's milk peptides in order to facilitate acquirement of tolerance is another possible argument in favor of the EHF.

Based on theoretical cost calculation, some have suggested AAF as diagnostic elimination diet or as initial management. $^{44,64,65}$ In Australia, already in 2009, a proposal was made to use AAF as the initial dietary intervention for CMA because of an economic benefit, potentially releasing limited hospital resources for alternative use within the pediatric healthcare system. ${ }^{64}$ In Brazil, it was calculated that the use of AAFs in the diagnostic elimination diet of infants ( $\leq 24$ months) with suspected CMA would be cost saving, and also result in more symptom free days. ${ }^{65}$ Similar recommendations were made in Turkey and China. ${ }^{44,66,67}$ In China, the new expert consensus on food allergy-related gastrointestinal diseases recommends using AAF for infants diagnosed with CMA. ${ }^{66,67}$

One could indeed consider the concept of an AAF based diagnostic elimination diet during 2-4 weeks. Arguments in favor of this concept include the fact that in case of CMA, an AAF should be $100 \%$ effective and thus result in a clearer response to a diagnostic elimination diet, since a number of infants will still react to the EHF. Also, it may result in faster resolution of symptoms, potentially enhancing the quality of life. However, only economic driven data are available to substantiate this hypothesis. An argument against using an AAF for diagnostic purposes is after the disappearance of symptoms with the AAF and relapse of symptoms during the challenge, the tolerance of the EHF still needs to be demonstrated. In many countries, unnecessary continuation of an AAF therapeutic diet and as a result increased cost may be a risk related to this approach. Last but not least, the impact on induction of oral tolerance should be considered and studied, since AAF is cow milk free. Therefore, well-designed prospective and blind trials are needed to further evaluate this new approach. 
In summary: AAF is recommended for severe CMA. The benefit-cost effect of an AAF based diagnostic elimination diet during 2 to 4 weeks before the diagnostic challenge seems a possibly interesting approach which should be evaluated before it can be recommended.

\section{Partial Hydrolysate Formulas (pHFs)}

Partially hydrolyzed cow's milk-based formulas have no place in the management of CMA because the residual allergenicity of the peptides in these formulas is too high, exposing the infant to a risk of severe reactions. As a consequence, the data on the efficacy of pHFs in CMA are extremely scarce. However, one study reported a $64 \%$ efficacy of a pHF in infants with $\operatorname{IgE} /$ mixed or non-IgE CMA with a positive double-blind challenge to cow's milk. ${ }^{68}$ These finding were confirmed in a Japanese study, showing that in 1-9 year old children with mild to moderate IgE mediated CMA, $20 \mathrm{~mL}$ of cow milk was tolerated by $2 / 25,20 \mathrm{~mL}$ of pHF by $16 / 25$ and $20 \mathrm{~mL}$ of EHF by $22 / 25 .{ }^{69}$ These authors conclude: "although further confirmation from additional centers is needed, our findings suggest the use of $\mathrm{pHF}$ in patients with mild CMA" ${ }^{69}$ Peptides with a tolerogenic potential have been identified in $\mathrm{pHF}^{70}$ In a mouse model, partially hydrolyzed whey proteins were shown to prevent clinical symptoms in a cow's milk allergic mice and enhance regulatory $\mathrm{T}$ and $\mathrm{B}$ cell frequencies. ${ }^{71}$ In other words: although $\mathrm{pHF}$ cannot be recommended in the management of CMA, improvement or even disappearance of symptoms with a pHF does not exclude CMA as a possible diagnosis. Also, pHF have been shown to result in adequate nutrition. In summary: pHF cannot be recommended in the management of CMA but CMA cannot be excluded if symptoms improve or disappear with a pHF since about half of the infants with CMA tolerate a pHF.

\section{Other Mammalian Milks}

It is contraindicated to feed an infant with CMA a formula with intact protein from other animals, including goat and sheep, because of a high cross-over allergenicity and possible nutritional inadequacy. In terms of allergenicity, the greatest level of cross-reaction is seen between cow's, sheep/ewe's and goat's milk. Less similarity is found between cow's milk and the milk from pig, horse, donkey and camels. ${ }^{32}$ In particular, camel and dromedary milk does not contain Bos d5. ${ }^{32}$

Noteworthy, the calcium content of mare's and donkey's milk is lower than cow's milk; the folate and vitamin B12 content of buffalo, sheep and goat's milk is lower than cow's milk and uncertain for other milks. ${ }^{32}$ There is some literature that donkey's milk and camel milk could be tolerated in selected infants, but to the best of our knowledge- there is no donkey milk or camel milk based nutritionally adapted formula in Europe on the market. ${ }^{72-75}$ Raw natural camel's or donkey's milk should not be considered in the management of CMA in infants.

\section{Plant-Based Based Infant Formula Rice-Based Formula}

Rice based infant formulas and hydrolysates have been commercially available for the last 30 years and consumption has risen, but rice based hydrolyzed formulas (RHFs) are not available in all countries. ${ }^{76}$ Sales data from France indicated that it accounted for $5 \%$ in volume of all formulas for children aged $0-3$ years in $2018 .{ }^{77}$

A RHF was shown to be tolerated by infants allergic to cow's milk and soy. ${ }^{77-79}$ With the same RHF tested in 100 infants with CMA, blood sera often contained specific IgE against rice proteins at Pharmacia ImmunoCAP ${ }^{\mathrm{TM}}$ (21/91) and immunoblotting (70/96) ${ }^{79}$ However, only six had very weakly positive responses according to skin prick tests and/or specific IgE to RHF, and all DBPCFC with RHF were negative. ${ }^{79}$ Efficacy and safety were also confirmed in a Spanish study. ${ }^{80}$ RHF was proposed to be more effective than soy and comparable to a casein hydrolysate in infants with CMA. ${ }^{81}$ The number of studies with RHF in infants with CMA remains limited compared to the number of studies with EHF.

Cost and palatability should also be considered. Four studies have assessed the taste acceptance of RHFs in adults and found better taste compared to EHF casein and similar taste acceptance to EHF whey formula. ${ }^{82}$ Initially, RHF were remarkable cheaper than EHFs. However, the cost of RHFs differs now from country to country: while in some countries RHFs are still cheaper in some countries, they have a comparable cost as EHFs in other countries.

The nutritional quality of rice proteins is suitable to be used in infant formulas giving that it is supplemented by certain amino acids that can be lacking. ${ }^{83}$ Infants fed a RHF for 6 months showed normal growth, normal plasma nutritional parameters and no adverse reactions. ${ }^{84-86}$ No significant differences between RHF, soy infant formula and casein EHF groups were observed for the z-score for weight-for-age during the first two years of life. ${ }^{85,86}$ A RHF was shown to be effective and 
nutritionally adequate, ${ }^{81,87,88}$ unlike rice beverages made from rice flour which are nutritionally inadequate. ${ }^{81}$

In one trial cow's milk tolerance was achieved earlier in infants fed RHF than in the ones receiving an EHF. ${ }^{89}$ However, another study concluded that acquisition of tolerance was faster with a casein EHF than with a RHF, and tolerance was further enhanced by the addition of Lactobacillus GG to the casein EHF. ${ }^{90}$ The absence of lactose in RHF and in most EHFs are still a topic of debate.

The high content of arsenic in some rice products, rice drinks and rice cereals has been considered in several studies and was the object of an FDA warning and an ESPGHAN Nutrition Committee document. ${ }^{91-93}$ However, in RHF the arsenic content was reported to be very low, and not different from the arsenic content of cow milk based infant formula. ${ }^{94}$

Already in 2010 the DRACMA guidelines suggested that HRF was a suitable alternative, depending on local availability, when EHF or soy protein based formulas were not tolerated. ${ }^{32}$ Since then, more data has been published on its safety and its availability has grown, resulting in its possible use as first line formula for CMA.

In summary: RHF are reported to be effective in the management on infants with CMA as first line option, when breastmilk is not available or if EHF are not accepted for taste reasons, not affordable or given lack of efficacy. ${ }^{77}$ There is no safety concern regarding RHF, on condition their arsenic content is controlled and within the safety remits set by the WHO. ${ }^{77,95}$ In the guidelines, there is no recommendation that RHF is preferable to soy formula, but that it can be substituted if available. ${ }^{32,37}$ Today, it is our opinion that RHFs may become preferable to soy formula as a plant-based alternative to EHF (see "soy based infant formula").

\section{Soy-Based Infant Formula}

Soy has been cultivated since the 17th century and is the third most important crop after rice and corn. Soy infant formula is historically the first plant-based feed for infants and young children that was developed. The first use of soy based infant feeding was reported in the United States in $1909 .{ }^{96}$ Noteworthy, to be nutritional adequate plantbased formula, ie soy protein isolate formula, should be fortified with some key nutrients, such as calcium, iron and dietary fiber. Besides availability and palatability, personal beliefs, religious background, and contemporary views advocating the importance of plant-based food in adult population are reasons which influence nutritional choices. ${ }^{97}$ According to the AAP, 10 to $14 \%$ of the infants with CMA will also become allergic to soy. ${ }^{98}$ Soy does cause less frequent allergic reactions in infants with $\operatorname{IgE}$ mediated allergy than in those with non-IgE mediated allergy. According to a systematic review, prevalence of soy allergy was 0 to $0.5 \%(0.27)$ in the general population, 0.4 to $3.1 \%$ (1.9) in the referred population, and 0 to $12.9 \%$ (2.7) in children already allergic to other foods. ${ }^{99}$ Prevalence of sensitization after the use of soy formulas is 8.7 and $8.8 \%$, depending on the method used. ${ }^{99}$ Although it is generally recommended not to use soy formula in infants aged less than six months, there is insufficient evidence that proves a higher risk of allergy in the first months of life. ${ }^{99}$ In some countries, where EHFs are not available or not affordable and the mother is unable to breastfeed, the use of soy formula as an alternative to cow's milk formula is preferable to other locally produced cow's milk alternative feeds that have not been proven as nutritionally complete for infant feeding, even in infants under the age of 6 months. ${ }^{99}$

Soy infant formula is not recommended as a firstchoice option in the management of infants with CMA. ${ }^{38}$ However, due to the unavailability and high cost of EHF or other dietary management options, soy infant formula is still used in many countries, especially developing ones. Heat treatment and extraction during processing also lower some unfavorable ingredients, such as isoflavone, trypsin inhibitor, phytic acid content, beany flavor. ${ }^{100,101}$ Soy protein isolate has a PDCAAS (Protein DigestibilityCorrected Amino Acid Score) of 1 which is comparable to high quality animal protein such as casein and egg white. ${ }^{102}$ Modern soy based infant formulas are evidencebased safe options to feed children. The patterns of growth, bone health and metabolic, reproductive, endocrine, immune and neurological functions have been reported to be similar to those observed in children fed cow's milk based infant formula or human milk. ${ }^{103}$

In summary: soy infant formula is a good secondary choice option in the management of non-breastfed infants with CMA when EHF or RHF or AAF are not available or not affordable.

\section{Other Plant-Based Beverages}

Whilst there are now some plant-based beverages (in particular based on soy) that are designed for toddlers, the primary concern is around energy, protein and selected micronutrient content (ie iodine and vitamin 
D). Most non-organic plant-based drinks are supplemented with calcium. However, many plant-based drinks are on the market and not nutritionally adapted to the needs of infants and toddlers and should, therefore, not be used as main drinks for children under 2 years of age. ${ }^{32,104}$ Adverse effects from the misuse of certain plant-based beverages have been well-documented and include failure to gain weight, decreased stature, kwashiorkor, electrolyte disorders, kidney stones, and severe nutrient deficiencies including iron deficiency anemia, rickets, and scurvy. Such adverse nutritional outcomes are largely preventable. ${ }^{105}$ However, recently, some toddler formulas have become available that are vegan, and made from clean real food ingredients such as pea, rice, buckwheat and almond, have a mild pleasant flavor, and meet $100 \%$ of the nutrient needs. Up to now, no other formulas nutritionally adapted to the needs of infants, except the rice based and soy formulas discussed above are available; but are now being studied. It is, however, conceivable difficult for the consumer and health care providers to separate the nutritionally adequate from the lessadapted plant-based beverages, drinks and feeds.

These plant-based beverages should ideally not be used as a main drink in children $<2$ years of age and if they are considered after 1 year of age, a nutritional assessment should occur before, to ensure that the child is achieving their nutritional requirements through their current diet. ${ }^{106}$

Plant based liquid feeds based on almond, buckwheat, rice and pea that are nutritionally adequate for toddlers are available for purchase in some countries and on-line. These plant-based drinks based on variety of grains and pulses have different tastes and characteristics. Some can be allergenic, including oat and almond milk and some are emerging allergens (ie pea). A Canadian case-series published on anaphylaxis to hidden pea protein. ${ }^{107}$ In peanut-sensitive patients, crossallergenicity was demonstrated to be most marked between the extracts of peanut, garden pea, chickpea, and soybean. ${ }^{108}$ The results have important implications for selection of effective hypoallergenic diets and for the diagnosis of patients hypersensitive to foods. ${ }^{108}$ The marketing positioning of these plant-based products as alternatives for patients with CMA is not substantiated with evidence and needs further well designed trials before these allegations can be endorsed. For rice drinks, unlike for HRF, concern has been raised about the arsenic content.
Also, for these other plant-based drinks, the absence of cow milk peptides to induce tolerance to cow milk protein and the absence of lactose are topics of debates.

In summary: the majority of other plant-based drinks on the market are nutritionally not adapted for infants and toddlers. However, growing up toddler formula from other plant based sources nutritionally adapted (almond, buckwheat, pea) are available. This evolution may warrant the development of a new terminology to differentiate the nutritionally inadequate "drinks" or "beverages" from the nutritionally adapted "liquid plant-based feedings or formulas". There is insufficient evidence to recommend these as alternative management options for infants and toddlers with CMA.

\section{The Gastrointestinal Microbiome A Bridge Between Pathogenesis and Management}

While the composition of the gastro-intestinal (GI) microbiome and its manipulation is not a main factor in the management of CMA, it is interfering independent of the dietary management option chosen. There is an increasing body of evidence showing that the composition of the GI microbiome is a key factor in the development of immune function. ${ }^{109,110}$ Dysbiosis may result in a disruption of the mucosal immunological tolerance and trigger pro-allergic and inflammatory processes, which lead to atopic conditions. ${ }^{109}$ Data from 20 years ago show that the GI microbiome composition in infants is prognostic to the development of CMA even before the onset of symptoms. ${ }^{111,112}$ It has been shown, already some 20 years ago, that a GI microbiome with low levels of bifidobacteria is observed in infants who will later become allergic. ${ }^{111,112}$ Lower relative abundances of certain bacteria (for example, Bifidobacterium, Akkermansia and Faecalibacterium), higher relative abundance of particular fungi (Candida and Rhodotorula) and a distinct fecal metabolome enriched for pro-inflammatory metabolites is a risk factor for the development of allergy. ${ }^{113}$ Neonatal gut microbiome dysbiosis might promote the CD4+ $\mathrm{T}$ cell dysfunction associated with childhood atopy. ${ }^{114}$ The onset of this mechanism might well be before birth. ${ }^{113}$ A greater relative abundance of Bacteroidaceae, Clostridiaceae, and Enterobacteriaceae and a lower relative concentration of Bifidobacteriaceae and Lactobacillaceae is associated with the development of allergic sensitization, eczema, or asthma. ${ }^{115}$ In light of this, modulation of the GI microbiome is a potential 
preventive and therapeutic target in infants with CMA. ${ }^{109}$ The GI microbiota synthesize bacterial metabolites, linking the microbiome, nutrition and the immune system. The main metabolites produced by gut microbiome are short-chain fatty acids (SCFAs). SCFAs have multiple beneficial effects on human health including protective effects in autoimmune and inflammatory diseases. ${ }^{116}$ Among SCFAs, butyrate is essential for maintaining gut immune homeostasis and exerts a pivotal role in immune tolerance with strong anti-inflammatory effects in allergic diseases. ${ }^{117}$ Recent findings suggest that butyrate takes part in the development of immunological tolerance to food, especially in the first 1000 days of life. ${ }^{117}$

Modulation of the infant gut microbiota with pre-, pro, or synbiotics as part of an EHF or AAF or as a supplement to formulas has been reported to reduce symptoms in atopic dermatitis and resolve CMA earlier. ${ }^{118}$ The addition of specific probiotic strains, such as Lactobacillus rhamnosus GG, was found to enhance the acquisition of oral tolerance more rapidly in infants with CMA, but further studies are needed. ${ }^{90,119}$

The presence of lactose in an EHF might be of additional benefit because of its effect on the composition of the GI microbiome through its possible prebiotic function. Lactose decreases stool $\mathrm{pH}$ and is associated with an increase of lactobacilli and bifidobacteria, and a decrease of potential pathogens in the GI microbiota. ${ }^{120,121}$ In addition, lactobacilli are associated with improved calcium absorption. $^{121}$ Thus, in the absence of secondary lactase deficiency, which may be a consequence of GI manifestations of CMA due to brush border damage, an elimination diet that includes medical grade lactose, that is not contaminated with cow's milk protein, may have a positive impact on the composition of the GI microbiome.

Other factors, such as the attendance to kindergarten and the presence of siblings may increase the risk of doctor-diagnosed lower respiratory tract infections in the first year of life in allergy-prone children. ${ }^{122}$ Secondary outcomes of randomized controlled trials (RCTs) suggest a decreasing trend in hospitalizations, infections and antibiotics and concurrent medication use in CMA-infants on an elimination diet containing pre-, and/or probiotics compared to those who were given an elimination diet without 'biotics'. ${ }^{123,124}$ However, none of these studies had one of these outcomes as primary endpoint. Nonetheless, studies were underpowered for these outcomes, which were often post-hoc analyses. To date, guidelines do not make specific recommendations on the use of probiotics and prebiotics in the management of CMA because of a lack of conclusive evidence. $^{125}$ The World Allergy Organization (WAO) guidelines considered that the modulation of the immune system using functional foods offers a promising research hypothesis as part of efforts to induce a tolerogenic immune environment in the context of CMA. ${ }^{125}$

In summary: there are currently no guideline recommendations for the use of "biotics" (pro-, pre-, syn- or postbiotics) for the prevention or treatment of CMA. However, there is evidence from basic and animal research that a high bifidogenic GI microbiome has health promoting effects as it decreases the risk for infections and stimulates the development of a balanced immune system, possibly reducing inflammation and allergy. Most clinical data in infants fail to demonstrate an additional beneficial effect of "biotics" added to the therapeutic elimination diet. However, there is humble evidence that a bifidogenic rich GI microbiota is skewing a balanced development of the immune system in all infants. Moreover, secondary outcomes of studies in presumed healthy and allergic infants suggest a decrease of infectious disease and antibiotic prescriptions. Therefore, the addition of "biotics" to a therapeutic hypo-allergenic diet in CMA infants can be recommended, even if there is no clear benefit regarding the efficacy of the elimination diet.

\section{Oral Immunotherapy}

Food oral immunotherapy (OIT) is a promising treatment for persistent and severe food allergies (FA) in children and for accelerating tolerance. ${ }^{126}$ OIT consists in daily ingestion of increasing doses of the allergen during the updosing phase, and ingestion of a constant dose during the maintenance phase based on specific tailored protocols. ${ }^{126}$

Indications and safety of oral immunotherapy (OIT) in infants and children with CMA are debated. Some centers recommend OIT in infants with IgE-mediated CMA under the age of one year. ${ }^{127,128}$ OIT is limited to patients with IgE-mediated CMA and it is the method of choice of prevention from anaphylaxis and severe accidental exposure. Introducing baked milk products into the diet of patients with milk allergy can accelerate the tolerance of unheated milk in these patients. ${ }^{129}$ The role of sIgE levels of milk, casein, and beta-lactoglobulin is controversial as some authors conclude that these did not predict the tolerance of unheated milk, while others came to opposite conclusions. $^{129,130}$ The high percentage of patients able to tolerate baked goods enables an improvement in intake possibilities and quality of life of CMA patients and 
families. ${ }^{130}$ Some authors even suggest that yoghurt is tolerated in infants with CMA. ${ }^{131}$

While some authors report almost absence of adverse effects, other report these are frequent, notably aversion to the allergen and oral syndromes as well as systemic allergic symptoms. ${ }^{126-128}$ EoE develops in $5.3 \%$ of children during OIT for CMA was reported. ${ }^{128}$

In summary, OIT in children with severe and persistent CMA deserves consideration, but at this time this approach should be reserved to selected patients and specialized centers. More evidence is needed before introducing OIT in infants in an Office-Based Practice, under the watchful eye of an health care provider.

\section{Long Term}

Long-term management of all food allergies requires education and risk assessment in addition to elimination diets. Health care providers need to make patients, their families, close relatives, and caregivers be aware of risk situations and instruct in reading labels and how to avoid cow's milk both in and outside the home. Patients at risk of anaphylaxis need to be taught to prescribe and use adrenaline auto-injectors.

While IgE determination has no place in the diagnosis of CMA in non-IgE mediated allergy, the level of $\operatorname{IgE}$ increase does have predictive value regarding the development of tolerance: the higher the IgE level, the greater the risk that CMA will persist. ${ }^{129}$ Challenge is recommended after 6-9 months of a therapeutic elimination diet or when the infant reaches the age of one year (whatever of both is reached first, independent of the type of allergy, with the exception of anaphylaxis). ${ }^{22,23}$ However, there is no global standardized recommended protocol on how to perform a challenge. Although, scientifically, a double-blind placebo- controlled challenge is definitely the best option, it is difficult to perform and costly. Therefore, an open challenge is used particularly in infants. While some protocols adhere to a steadily increasing allergens by small volumes over a couple of hours, ${ }^{22,23}$ others, such as the iMAP guidelines recommended only for non-IgE mediated CMA a ladder approach starting with baked milk and stepping up in volume and processing of cow's milk protein over days and weeks, and also gradually change the structure of the protein source. ${ }^{132}$ The reality is that many parents refuse a properly performed challenge test because of its complexity and because of the fear of reappearance of symptoms in their children. In a randomized comparative trial where both parents signed an informed consent to perform a challenge test, $23 \%$ refused. $^{133}$ The older the child becomes, the less "milk" is an essential part of the dietary intake.

\section{Conclusion}

Breast milk remains the gold standard source of nutrition in all children, including those with CMA. Guidelines recommend CMP-eHF as first choice management in infants with mild to moderate CMA. AAFs are indicated when there is severe CMA, such as in the presence of anaphylaxis or failure to thrive or in cases not responding to EHFs. As some infants with CMA will not tolerate EHF, AAF as well as RHFs have been recently proposed to be used during the diagnostic elimination diet period before the challenge. Today, no guideline recommends the addition of "biotics" to the elimination diet. However, increasing evidence indicates that the gastrointestinal microbiome is important for infant health and an altered microbiota may influence the development of allergy and possible acquisition of tolerance. Therefore, the supplementation of all infant artificial feedings, including therapeutic elimination diets, with different components such as probiotics, prebiotics, lactose and others that stimulate the development of a bifidogenic rich microbiome should be considered in the future.

\section{Disclosure}

YV has participated as a clinical investigator, and/or advisory board member, and/or consultant, and/or speaker for Abbott Nutrition, Ausnutria, Biogaia, By Heart, CHR Hansen, Danone, ELSE Nutrition, Friesland Campina, Nestle Health Science, Nestle Nutrition Institute, Nutricia, Mead Johnson Nutrition, Phathom Pharmaceuticals, United Pharmaceuticals (Novalac), Yakult, Wyeth.

HB reports receiving research grants from the National Institutes of Health (NIH) (U01 \# AI147462), Aimmune and DBV Technologies and speaker fees from DBV Technologies and Sanofi outside of the submitted work.

AF has participated as an advisory board member, consultant, and/or speaker for Abbott Nutrition, Danone, Nutricia, Ordesa, Humana, and Hipp.

MM has participated as an advisory board member, and/ or speaker for Abbott Nutrition, Ausnutria, Biogaia, Danone, Friesland Campina, Nestle Nutrition Institute, Nutricia, United Pharmaceuticals (Novalac), and Wyeth.

SS has participated as a clinical investigator, and/or advisory board member, and/or consultant, and/or speaker 
for Danone-Mellin, DVA, Noos, Nestlé, United Pharmaceuticals (Novalac).

NT has participated as an advisory board member, and/ or consultant, and/or speaker for Danone, Nutricia and Takeda.

CV reports grants from Reckitt Benckiser, Food Allergy Research and Education, National Peanut Board; personal fees from Reckitt Benckiser, Nestle Nutrition Institute, Danone, Abbott Nutrition, Else Nutrition, Before Brands.

$\mathrm{MCV}$ reports personal fees as a consultant and/or speaker from Danone Nutricia and Nestlé Nutrition Institute, outside the submitted work.

RM has participated as an advisory board member, and/ or consultant, and/or speaker for Abbott Nutrition, Danone, Nestle Health Science, Nutricia and Mead Johnson Nutrition.

The authors report no other conflicts of interest in this work.

\section{References}

1. Schoemaker AA, Sprikkelman AB, Grimshaw $\mathrm{KE}$, et al. Incidence and natural history of challenge-proven cow's milk allergy in European children - EuroPrevall birth cohort. Allergy. 2015;70(8):963-972. doi:10.1111/all.12630

2. Meyer R, Groetch M, Venter C. When should infants with cow's milk protein allergy use an amino acid formula? a practical guide. J Allergy Clin Immunol Pract. 2018;6:383-399. doi:10.1016/j. jaip.2017.09.003

3. Latcham F, Merino F, Lang A, et al. A consistent pattern of minor immunodeficiency and subtle enteropathy in children with multiple food allergy. J Pediatr. 2003;143:39-47. doi:10.1016/S00223476(03)00193-8

4. Salvatore S, Agosti M, Baldassarre ME, et al. Cow's milk allergy or gastroesophageal reflux disease - can we solve the dilemma in infants? Nutrients. 2021;13:297. doi:10.3390/nu13020297

5. Nowak-Wegrzyn A, Katz Y, Mehr SS, Koletzko S. Non-IgEmediated gastrointestinal food allergy. J Allergy Clin Immunol. 2015;135:1114-1124. doi:10.1016/j.jaci.2015.03.025

6. Meyer R. Nutritional disorders resulting from food allergy in children. Pediatr Allergy Immunol. 2018;29:689-704. doi:10.1111/pai.12960

7. Mehta H, Groetch M, Wang J. Growth and nutritional concerns in children with food allergy. Curr Opin Allergy Clin Immunol. 2013;13:275-279. doi:10.1097/ACI.0b013e328360949d

8. Robbins KA, Wood RA, Keet CA. Milk allergy is associated with decreased growth in US children. J Allergy Clin Immunol. 2014;134:1466-1468 e6. doi:10.1016/j.jaci.2014.08.037

9. Diaferio L, Caimmi D, Verga MC, et al. May failure to thrive in infants be a clinical marker for the early diagnosis of cow's milk allergy? Nutrients. 2020;12:466. doi:10.3390/nu12020466

10. Vieira MC, Morais MB, Spolidoro JV, et al. A survey on clinical presentation and nutritional status of infants with suspected cow ${ }^{\text {* }}$ milk allergy. BMC Pediatr. 2010;10(1):25. doi:10.1186/14712431-10-25

11. D'Auria E, Fabiano V, Bertoli S, et al. Growth pattern, resting energy expenditure, and nutrient intake of children with food allergies. Nutrients. 2016;11:212. doi:10.3390/nu11020212
12. Meyer R, De Koker C, Dziubak R, et al. The impact of the elimination diet on growth and nutrient intake in children with food protein induced gastrointestinal allergies. Clin Transl Allergy. 2016;6:25. doi:10.1186/s13601-016-0115-x

13. Meyer R, Wright K, Vieira MC, et al. International survey on growth indices and impacting factors in children with food allergies. J Hum Nutr Diet. 2019;32:175-184. doi:10.1111/ jhn. 12610

14. Kvammen JA, Thomassen RA, Eskerud MB, Rugtveit J, Henriksen C. Micronutrient status and nutritional intake in 0 - to 2-year-old children consuming a cows' milk exclusion diet. J Pediatr Gastroenterol Nutr. 2018;66:831-837. doi:10.1097/ MPG.0000000000001942

15. Indinnimeo L, Baldini L, De Vittori V, et al. Duration of a cowmilk exclusion diet worsens parents' perception of quality of life in children with food allergies. BMC Pediatr. 2013;13:203. doi:10.1186/1471-2431-13-203

16. Maciag MC, Herbert LJ, Sicherer SH, et al. The psychosocial impact of food protein-induced enterocolitis syndrome. J Allergy Clin Immunol Pract. 2020;8:3508-3514.e5. doi:10.1016/j. jaip.2020.06.011

17. Stapel SO, Asero R, Ballmer-Weber BK, et al. Testing for IgG4 against foods in not recommended as a diagnostic tool: EAACI Task Force Report. Allergy. 2008;63:793-796. doi:10.1111/ j.1398-9995.2008.01705.x

18. Simon D, Cianferoni A, Spergel JM, et al. Eosinophilic esophagitis is characterized by a non-IgE-mediated food hypersensitivity. Allergy. 2016;71:611-620. doi:10.1111/all.12846

19. Lim AH, Wong S, Nguyen NQ. Eosinophilic esophagitis and IgG4: is there a relationship? Dig Dis Sci. 2021. doi:10.1007/ s10620-020-06788-0

20. Mehr S, Frith K, Barnes EH, Campbell DE; FPIES Study Group. Food protein-induced enterocolitis syndrome in Australia: a population-based study, 2012-2014. J Allergy Clin Immunol. 2017;140:1323-1330. doi:10.1016/j.jaci.2017.03.027

21. Abrams EM, Hildebrand KJ, Chan ES. Non-IgE-mediated food allergy: evaluation and management. Paediatr Child Health. 2021;26:173-181. doi:10.1093/pch/pxaa131

22. Koletzko S, Niggemann B, Arato A, et al. Diagnostic approach and management of cow's-milk protein allergy in infants and children: ESPGHAN GI Committee practical guidelines. J Pediatr Gastroenterol Nutr. 2012;55:221-229. doi:10.1097/ MPG.0b013e31825c9482

23. Vandenplas Y, Koletzko S, Isolauri E, et al. Guidelines for the diagnosis and management of cow's milk protein allergy in infants. Arch Dis Child. 2007;92:902-908. doi:10.1136/ adc.2006.110999

24. Koopman LP, Smit HA, Heijnen ML, et al. Respiratory infections in infants: interaction of parental allergy, child care, and siblingsthe PIAMA study. Pediatrics. 2001;108:943-948. doi:10.1542/ peds.108.4.943

25. D'Auria E, Salvatore S, Pozzi E, et al. Cow's milk allergy: immunomodulation by dietary intervention. Nutrients. 2019;11:1399. doi:10.3390/nu11061399

26. Nowak-Węgrzyn A, Chehade M, Groetch ME, et al. International consensus guidelines for the diagnosis and management of food protein-induced enterocolitis syndrome: executive summaryWorkgroup Report of the Adverse Reactions to Foods Committee, American Academy of Allergy, Asthma \& Immunology. J Allergy Clin Immunol. 2017;139:1111-1126.e4. doi:10.1016/j.jaci.2016.12.966

27. Omari T, Tobin JM, McCall L, et al. Characterization of Upper Gastrointestinal Motility in Infants With Persistent Distress and Non-IgE-mediated Cow's Milk Protein Allergy. J Pediatr Gastroenterol Nutr. 2020;70:489-496. doi:10.1097/MPG.000 0000000002600 
28. Venter C, Brown T, Meyer R, et al. Better recognition, diagnosis and management of non-IgE-mediated cow's milk allergy in infancy: iMAP-an international interpretation of the MAP (Milk Allergy in Primary Care) guideline. Clin Transl Allergy. 2017;7:26. doi:10.1186/s13601-017-0162-y

29. Calvani M, Anania C, Cuomo B, et al. Non-IgE- or mixed IgE/ Non-IgE-mediated gastrointestinal food allergies in the first years of life: old and new tools for diagnosis. Nutrients. 2021;13:226. doi: $10.3390 /$ nu 13010226

30. Nwaru BI, Hickstein L, Panesar SS, Roberts G, Muraro A, Sheikh A, EAACI Food Allergy and Anaphylaxis Guidelines Group. Anaphylaxis guidelines, prevalence of common food allergies in Europe: a systematic review and meta-analysis. Allergy. 2014;69:992-1007.

31. Vandenplas Y, Dupont C, Eigenmann P, et al. A workshop report on the development of the Cow's Milk-related Symptom Score awareness tool for young children. Acta Paediatr. 2015;104:334-339. doi:10.1111/apa.12902

32. Fiocchi A, Brozek J, Schünemann H, et al. World allergy organization (WAO) diagnosis and rationale for action against cow's milk allergy (DRACMA) guidelines. World Allergy Org J. 2010;3:57-161. doi:10.1097/WOX.0b013e3181defeb9

33. Dupont C, Chouraqui JP, Linglart A, et al.; Committee on Nutrition of the French Society of Pediatrics. Nutritional management of cow's milk allergy in children: an update. Arch Pediatr. 2018;25:236-243. doi:10.1016/j.arcped.2018.01.007

34. Luyt D, Ball H, Makwana N, et al. Standards of Care Committee (SOCC) of the British Society for Allergy and Clinical Immunology (BSACI). BSACI guideline for the diagnosis and management of cow's milk allergy. Clin Exp Allergy. 2014;44:642-672. doi:10.1111/cea.12302

35. Espin Jaime B, Diaz Martin JJ, Blesa Baviera LC, et al. Non-IgEmediated cow's milk allergy: consensus document of the Spanish Society of Paediatric Gastroenterology, Hepatology, and Nutrition (SEGHNP), the Spanish Association of Paediatric Primary Care (AEPAP), the Spanish Society of Extra-hospital Paediatrics and Primary Health Care (SEPEAP), and the Spanish Society of Paediatric ClinicaL Immunology, Allergy, and Asthma (SEICAP)]. An Pediatr. 2019;90:193.e191-193.e111. doi:10.1016/j.anpedi.2018.11.007

36. Kramer MS, Kakuma R. Maternal dietary antigen avoidance during pregnancy or lactation, or both, for preventing or treating atopic disease in the child. Evid Based Child Health. 2014;9:447-483. doi:10.1002/ebch.1972

37. Muraro A, Werfel T, Hoffmann-Sommergruber K, et al. EAACI food allergy and anaphylaxis guidelines: diagnosis and management of food allergy. Allergy. 2014;69:1008-1025. doi:10.1111/all.12429

38. Vandenplas Y, Al-Hussaini B, Al-Mannaei K, et al. Prevention of allergic sensitization and treatment of cow's milk protein allergy in early life: the Middle-East step-down consensus. Nutrients. 2019;11:1444. doi:10.3390/nu11071444

39. American Academy of Pediatrics. Committee of Nutrition. Hypoallergenic formulas. Pediatrics. 2000;106:346-349.

40. Host A, Koletzko B, Dreborg S, et al. Dietary products used in infants for treatment and prevention of food allergy. Joint Statement of the European Society for Paediatric Allergology and Clinical Immunology (ESPACI) Committee on Hypoallergenic Formulas and the European Society for Paediatric Gastroenterology, Hepatology and Nutrition (ESPGHAN) Committee on Nutrition. Arch Dis Child. 1999;81:80-84. doi:10.1136/adc.81.1.80

41. Caffarelli C, Plebani A, Poiesi C, Petroccione T, Spattini A, Cavagni G. Determination of allergenicity to three cow's milk hydrolysates and an amino acid-derived formula in children with cow's milk allergy. Clin Exp Allergy. 2002;32:74-79. doi:10.1046/j.0022-0477.2001.01262.x
42. Isolauri E, Sutas Y, Makinen-Kiljunen S, Oja SS, Isosomppi R, Turjanmaa K. Efficacy and safety of hydrolyzed cow milk and amino acid-derived formulas in infants with cow milk allergy. $J$ Pediatr. 1995;127:550-557. doi:10.1016/s0022-3476(95) 70111-7

43. de Boissieu D, Matarazzo P, Dupont C. Allergy to extensively hydrolyzed cow milk proteins in infants: identification and treatment with an amino acid-based formula. $J$ Pediatr. 1997;131:744-747. doi:10.1016/s0022-3476(97)70104-5

44. Berktas M, Kirbiyik F, Aribal E, Aksit A, Altintas DU. Treatment options for cow's milk protein allergy: a modeling analysis. Clinicoecon Outcomes Res. 2020;12:307-315. doi:10.2147/CEOR. S242021

45. Ammar F, de Boissieu D, Dupont C. Allergy to protein hydrolysates. Report of 30 cases. Arch Pediatr. 1999;6:837-843. doi:10.1016/s0929-693x(00)88476-6

46. Agostoni C, Terracciano L, Varin E, Fiocchi A. The nutritional value of protein-hydrolyzed formulae. Crit Rev Food Sci Nutr. 2016;5:65-69. doi:10.1080/10408398.2012.713047

47. Borschel MW, Ziegler EE, Wedig RT, Oliver JS. Growth of healthy term infants fed an extensively hydrolyzed casein-based or free amino acid-based infant formula: a randomized, double-blind, controlled trial. Clin Pediatr. 2013;52:910-917. doi: $10.1177 / 0009922813492883$

48. Borschel MW, Baggs GE, Oliver JS. Comparison of growth of healthy term infants fed extensively hydrolyzed protein- and amino acid-based infant formulas. Nutrients. 2018;10:289. doi:10.3390/nu10030289

49. Borschel MW, Choe YS, Kajzer JA. Growth of healthy term infants fed partially hydrolyzed whey-based infant formula: a randomized, blinded, controlled trial. Clin Pediatr. 2014;53:1375-1382. doi:10.1177/0009922814541804

50. Vandenplas Y, Steenhout P, Planoudis Y, Grathwohl D; Althera Study Group. Treating cow's milk protein allergy: a double-blind randomized trial comparing two extensively hydrolysed formulas with probiotics. Acta Paediatr. 2013;102:990-998. doi:10.1111/ apa. 12349

51. Nutten S, Maynard F, Järvi A, et al. Peptide size profile and residual immunogenic milk protein or peptide content in extensively hydrolyzed infant formulas. Allergy. 2020;75:1446-1449. doi:10.1111/all.14098

52. Nutten S, Schuh S, Dutter T, Heine RG, Kuslys M. Design, quality, safety and efficacy of extensively hydrolyzed formula for management of cow's milk protein allergy: what are the challenges? Adv Food Nutr Res. 2020;93:147-204. doi:10.1016/ bs.afnr.2020.04.004

53. Agostoni C, Terracciano L, Varin E, Fiocchi A. The nutritional value of protein-hydrolyzed formulae. Crit Rev Food Sci Nutr. 2016;56:65-69. doi:10.1080/10408398.2012.7 13047

54. Del Giudice M, D'Auria E, Peroni D, et al. Flavor, relative palatability and components of cow's milk hydrolysed formulas and amino acid-based formula. Ital $J$ Pediatr. 2015;41:42. doi:10.1186/s13052-015-0141-7

55. Maslin K, Fox AT, Chambault M, Meyer R. Palatability of hypoallergenic formulas for cow's milk allergy and healthcare professional recommendation. Pediatr Allergy Immunol. 2018;29:857-862. doi:10.1111/pai.12979

56. Mennella JA, Castor SM. Sensitive period in flavor learning: effects of duration of exposure to formula flavors on food likes during infancy. Clin Nutr. 2012;31:1022-1025. doi:10.1016/j. clnu.2012.05.005

57. Maslin K, Grimshaw K, Oliver E, et al. Taste preference, food neophobia and nutritional intake in children consuming a cows' milk exclusion diet: a prospective study. J Hum Nutr Diet. 2016;29:786-796. doi:10.1111/jhn.12387 
58. Corkins M, Czerkies LA, Storm HM, Sun S, Saavedra JM. Assessment of growth of infants fed an amino acid-based formula. Clin Med Insights Pediatr. 2016;10:3-9. doi:10.4137/ CMPed.S33071

59. Burks AW, Harthoorn LF, Van Ampting MT, et al. Synbioticssupplemented amino acid-based formula supports adequate growth in cow's milk allergic infants. Pediatr Allergy Immunol. 2015;26:316-322. doi:10.1111/pai.12390

60. Canani RB, Nocerino R, Frediani T, et al. Amino acid-based formula in cow's milk allergy: long-term effects on body growth and protein metabolism. $J$ Pediatr Gastroenterol Nutr. 2017;64:632-638. doi:10.1097/MPG.0000000000001337

61. Dupont C, Kalach N, Soulaines P, et al. Safety of a new amino acid formula in infants allergic to cow's milk and intolerant to hydrolysates. J Pediatr Gastroenterol Nutr. 2015;61:456-463. doi:10.1097/MPG.0000000000000803

62. Vandenplas Y, Dupont C, Eigenmann P, et al. Growth in infants with cow's milk protein allergy fed an amino acid-based formula. Pediatr Gastroenterol Hepatol Nutr. 2021;24:392-402. doi:10.5223/pghn.2021.24.4.392

63. Harvey BM, Eussen S, Harthoorn LF, Burks AW. Mineral intake and status of cow's milk allergic infants consuming an amino acid-based formula. $J$ Pediatr Gastroenterol Nutr. 2017;65:346-349. doi:10.1097/MPG.0000000000001655

64. Guest JF, Nagy E. Modelling the resource implications and budget impact of managing cow milk allergy in Australia. Curr Med Res Opin. 2009;25:339-349. doi:10.1185/03007990802594685

65. Morais M, Spolidoro JV, Vieira MC, et al. Amino acid formula as a new strategy for diagnosing cow's milk allergy in infants: is it cost-effective? J Med Econ. 2016;19:1207-1214. doi:10.1080/ 13696998.2016.1211390.

66. Gastroenterology Group, Pediatrics Branch, Chinese Medical Association. Expert consensus of food allergic gastrointestinal disease. Zhonghua Er Ke Za Zhi. 2017;55:487-492. doi:10.3760/cma.j.issn.0578-1310.2017.07.003

67. Chinese Medical Doctor Association Dermatology Branch Children Dermatology Professional Committee. Expert consensus on the diagnosis and management of food allergies related to atopic dermatitis in children. Chinese J Dermatol. 2019;52:711-716.

68. Giampietro PG, Kjellman NI, Oldaeus G, Wouters-Wesseling W, Businco L. Hypoallergenicity of an extensively hydrolyzed whey formula. Pediatr Allergy Immunol. 2001;12:83-86. doi:10.1034/ j.1399-3038.2001.012002083.x

69. Inuo C, Tanaka K, Nakajima Y, et al. Tolerability of partially and extensively hydrolysed milk formulas in children with cow's milk allergy. Asia Pac J Clin Nutr. 2019;28:49-56. doi:10.6133/ apjen.201903_28(1).0008

70. Gouw JW, Jo J, Meulenbroek LAPM, et al. Identification of peptides with tolerogenic potential in a hydrolysed whey-based infant formula. Clin Exp Allergy. 2018;48:1345-1353. doi:10.1111/cea.13223

71. Kiewiet MBG, van Esch BCAM, Garssen J, Faas MM, de Vos P. Partially hydrolyzed whey proteins prevent clinical symptoms in a cow's milk allergy mouse model and enhance regulatory $\mathrm{T}$ and B cell frequencies. Mol Nutr Food Res. 2017;61:11. doi:10.1002/ mnfr. 201700340

72. Mohammad S, Hazeima KA, Al-Mesaifri F, Bener A. Camel milk: an alternative for cow's milk allergy in children. Allergy Asthma Proc. 2011;32:255-258. doi:10.2500/aap.2011.32.3429

73. Talarico V, Mazza G, Rubino M, et al. Camel milk: a possible alternative for children with cow's milk allergy? Minerva Pediatr. 2019. doi:10.23736/S0026-4946.19.05632-9

74. Tesse R, Paglialunga C, Braccio S, Armenio L. Adequacy and tolerance to ass's milk in an Italian cohort of children with cow's milk allergy. Ital J Pediatr. 2009;35:19. doi:10.1186/1824-728835-19
75. Barni S, Sarti L, Mori F, et al. Tolerability and palatability of donkey's milk in children with cow's milk allergy. Pediatr Allergy Immunol. 2018;29:329-331. doi:10.1111/pai.12871

76. Gastañaduy A, Cordano A, Graham GG. Acceptability, tolerance, and nutritional value of a rice-based infant formula. $J$ Pediatr Gastroenterol Nutr. 1990;11:240-246. doi:10.1097/00005176199008000-00014

77. Bocquet A, Dupont C, Chouraqui JP, et al. Committee on Nutrition of the French Society of Pediatrics (CNSFP) Efficacy and safety of hydrolyzed rice-protein formulas for the treatment of cow's milk protein allergy. Arch Pediatr. 2019;26:238-246. doi:10.1016/j.arcped.2019.03.001

78. Fiocchi A, Travaini M, D'Auria E, Banderali G, Bernardo L, Riva E. Tolerance to a rice hydrolysate formula in children allergic to cow's milk and soy. Clin Exp Allergy. 2003;33:1576-1580. doi:10.1046/j.1365-2222.2003.01781.x

79. Fiocchi A, Restani P, Bernardini R, et al. A hydrolysed rice-based formula is tolerated by children with cow's milk allergy: a multicentre study. Clin Exp Allergy. 2006;36:311-316. doi:10.1111/ j.1365-2222.2006.02428.x

80. Reche M, Pascual C, Fiandor A, et al. The effect of a partially hydrolysed formula based on rice protein in the treatment of infants with cow's milk protein allergy. Pediatr Allergy Immunol. 2010;21:577-585. doi:10.1111/j.1399-3038.2010.00991.x

81. Agostoni C, Fiocchi A, Riva E, et al. Growth of infants with IgEmediated cow's milk allergy fed different formulas in the complementary feeding period. Pediatr Allergy Immunol. 2007;18:599-606. doi:10.1111/j.1399-3038.2007.00566.x

82. Pedrosa M, Pascual CY, Larco JI, Martin Esteban M. Cow's milk allergic children: a comparative study of taste, smell, and texture evaluated by healthy volunteers. J Investig Allergol Clin Immunol. 2006;16:351-356.

83. Dupont C, Bocquet A, Tomé D, et al. Hydrolyzed rice proteinbased formulas, a vegetal alternative in cow's milk allergy. Nutrients. 2020;12:2654. doi:10.3390/nu12092654

84. D’Auria E, Sala M, Lodi F, Radaelli G, Riva E, Giovannini M. Nutritional value of a rice-hydrolysate formula in infants with cows' milk protein allergy: a randomized pilot study. J Int Med Res. 2003;31:215-222. doi:10.1177/147323000303100308

85. Lasekan JB, Koo WW, Walters J, Neylan M, Luebbers S. Growth, tolerance and biochemical measures in healthy infants fed a partially hydrolyzed rice protein-based formula: a randomized, blinded, prospective trial. J Am Coll Nutr. 2006;25:12-19. doi:10.1080/07315724.2006.10719509

86. Savino F, Castagno E, Monti G, et al. Z-score of weight for age of infants with atopic dermatitis and cow's milk allergy fed with a ricehydrolysate formula during the first two years of life. Acta Paediatr Suppl. 2005;94:115-119. doi:10.1111/j.1651-2227.2005.tb02166.x

87. Vandenplas Y, De Greef E, Hauser B; Paradice Study Group. Safety and tolerance of a new extensively hydrolyzed rice protein-based formula in the management of infants with cow's milk protein allergy. Eur J Pediatr. 2014;173:1209-1216. doi:10.1007/ s00431-014-2308-4

88. Vandenplas Y, De Greef E, Hauser B; Paradice Study Group. An extensively hydrolysed rice protein-based formula in the management of infants with cow's milk protein allergy: preliminary results after 1 month. Arch Dis Child. 2014;99:933-936. doi:10.1136/archdischild-2013-304727

89. Terracciano L, Bouygue GR, Sarratud T, Veglia F, Martelli A, Fiocchi A. Impact of dietary regimen on the duration of cow's milk allergy: a random allocation study. Clin Exp Allergy. 2010;40:637-642. doi:10.1111/j.1365-2222.2009.03427.x

90. Berni Canani R, Nocerino R, Terrin G, et al. Formula selection for management of children with cow's milk allergy influences the rate of acquisition of tolerance: a prospective multicenter study. J Pediatr. 2013;163:771-777.e1. doi:10.1016/j.jpeds.2013.03.008 
91. Vela NP, Heitkemper DT. Total arsenic determination and speciation in infant food products by ion chromatography-inductively coupled plasma-mass spectrometry. $J$ AOAC Int. 2004;87:244-252.

92. Hojsak I, Braegger C, Bronsky J, et al.; ESPGHAN Committee on Nutrition. Arsenic in rice: a cause for concern. J Pediatr Gastroenterol Nutr. 2015;60:142-145. doi:10.1097/ MPG.0000000000000502

93. FDA warning. Guidance for industry: action level for inorganic arsenic in rice cereals for infants Available from: https://www.fda. gov/regulatory-information/search-fda-guidance-documents/gui dance-industry-action-level-inorganic-arsenic-rice-cereals-infants. Accessed October 12, 2021.

94. Meyer R, Carey MP, Turner PJ, Meharg AA. Low inorganic arsenic in hydrolysed rice formula used for cow's milk protein allergy. Pediatr Allergy Immunol. 2018;29:561-563. doi:10.1111/ pai.12913

95. Fiocchi A, Dahda L, Dupont C, Campoy C, Fierro V, Nieto A. Cow's milk allergy: towards an update of DRACMA guidelines. World Allergy Organ J. 2016;9:35. doi:10.1186/s40413-0160125-0

96. Ruhrah J. The soy bean in infant feeding: preliminary report. Arch Pediatr. 1909;26:496-501.

97. Berger-Achituv S, Shohat T, Romano-Zelekha O, et al. Widespread use of soy-based formula formula without clinical indications. J Pediatr Gastroenter Nutr. 2005;41:660-666. doi:10.1097/01.mpg.0000181855.77488.bf

98. Bhatia J, Greer F; American Academy of Pediatrics Committee on Nutrition. Use of soy protein-based formulas in infant feeding. Pediatrics. 2008;121:1062-1068. doi:10.1542/peds.2008-0564

99. Katz Y, Gutierrez-Castrellon P, González MG, Rivas R, Lee BW, Alarcon P. A comprehensive review of sensitization and allergy to soy-based products. Clin Rev Allergy Immunol. 2014;46:272-281. doi:10.1007/s12016-013-8404-9

100. Rickert DA, Johnson LA, Murphy PA. Improved Fractionation of Glycinin and $\beta$-Conglycinin and Partitioning of Phytochemicals J Agr Food Chem. 2004;52(6):1726-1734. doi:10.1021/ jf035248x

101. Goodnight KC Jr, Hartman GH, Marquardt RF Aqueous purified soy protein and beverage. US Patent 3995071; 1976.

102. Hughes GJ, Ryan DJ, Mukherjea R, Schasteen CS. Protein digestibility-corrected amino acid scores (PDCAAS) for soy protein isolates and concentrate: criteria for evaluation. J Agric Food Chem. 2011;59:12707-12712. doi:10.1021/jf203220v

103. Vandenplas Y, Gutierrez Castrellon P, Rivas R, et al. Safety of soya-based infant formulas in children. Br J Nutr. 2014;111:1340. doi: $10.1017 / \mathrm{S} 0007114513003942$

104. Meyer R, De KC, Dziubak R, Godwin H, Dominguez-Ortega G, Shah N. Dietary elimination of children with food protein induced gastrointestinal allergy - micronutrient adequacy with and without a hypoallergenic formula? Clin Transl Allergy. 2014;4:31. doi:10.1186/2045-7022-4-31

105. Merritt RJ, Fleet SE, Fifi A, et al.; NASPGHAN Committee on Nutrition. North American Society for Pediatric Gastroenterology, Hepatology, and Nutrition Position paper: plant-based milks. J Pediatr Gastroenterol Nutr. 2020;71:276-281. doi:10.1097/ MPG.0000000000002799

106. Groetch M, Venter C. Nutritional management of food allergies. Journal of Food Allergy. 2020;2:11. doi:10.2500/ jfa.2020.2.200032

107. Lavine E, Ben-Shoshan M. Anaphylaxis to hidden pea protein: a Canadian pediatric case series. J Allergy Clin Immunol Pract. 2019;7:2070-2071. doi:10.1016/j.jaip.2019.02.010

108. Barnett D, Bonham B, Howden ME. Allergenic cross-reactions among legume foods-an in vitro study. J Allergy Clin Immunol. 1987;79:433-438. doi:10.1016/0091-6749(87)90359-9
109. Pascal M, Perez-Gordo M, Caballero T, et al. Microbiome and allergic diseases. Front Immunol. 2018;9:1584. doi:10.3389/ fimmu.2018.01584

110. Zhao W, Ho HE, Bunyavanich S. The gut microbiome in food allergy. Ann Allergy Asthma Immunol. 2019;122:276-282. doi:10.1016/j.anai.2018.12.012

111. Kalliomäki M, Kirjavainen P, Eerola E, Kero P, Salminen S, Isolauri E. Distinct patterns of neonatal gut microflora in infants in whom atopy was and was not developing. J Allergy Clin Immunol. 2001;107:129-134. doi:10.1067/mai.2001.111237

112. Björkstén B, Sepp E, Julge K, Voor T, Mikelsaar M. Allergy development and the intestinal microflora during the first year of life. J Allergy Clin Immunol. 2001;108:516-520. doi:10.1067/ mai.2001.118130

113. Petersen C, Dai DLY, Boutin RCT, et al. A rich meconium metabolome in human infants is associated with early-life gut microbiota composition and reduced allergic sensitization. Cell Rep Med. 2021;2:100260. doi:10.1016/j.xcrm.2021.100260

114. Fujimura KE, Sitarik AR, Havstad S, et al. Neonatal gut microbiota associates with childhood multisensitized atopy and $\mathrm{T}$ cell differentiation. Nat Med. 2016;22:1187-1191. doi:10.1038/nm.4176

115. Zimmermann P, Messina N, Mohn WW, Finlay BB, Curtis N. Association between the intestinal microbiota and allergic sensitization, eczema, and asthma: a systematic review. J Allergy Clin Immunol. 2019;143:467-485. doi:10.1016/j.jaci.2018.09.025

116. Paparo L, Nocerino R, Ciaglia E, et al. Butyrate as a bioactive human milk protective component against food allergy. Allergy. 2021;76:1398-1415. doi:10.1111/all.14625

117. Di Costanzo M, De Paulis N, Biasucci G. Butyrate: a Link between Early Life Nutrition and Gut Microbiome in the Development of Food Allergy. Life. 2021;11:384. doi:10.3390/ life 11050384

118. Asai Y, Yanishevsky Y, Clarke A, et al. Rate, triggers, severity and management of anaphylaxis in adults treated in a Canadian emergency department. Int Arch Allergy Immunol. 2014;164:246-252. doi:10.1159/000365631

119. Sánchez-Valverde F, Etayo V, Gil F, et al. Factors Associated with the Development of Immune Tolerance in Children with Cow's Milk Allergy. Int Arch Allergy Immunol. 2019;179:290-296. doi:10.1159/000499319

120. Van den Abbeele P, Sprenger N, Ghyselinck J, Marsaux B, Marzorati M, Rochat F. A comparison of the In vitro effects of 2'Fucosyllactose and lactose on the composition and activity of gut microbiota from infants and toddlers. Nutrients. 2021;13:726. doi:10.3390/nu13030726

121. Francavilla R, Calasso M, Calace L, et al. Effect of lactose on gut microbiota and metabolome of infants with cow's milk allergy. Pediatr Allergy Immunol. 2012;23:420-427. doi:10.1111/j.13993038.2012.01286.x

122. Koopman LP, Smit HA, Heijnen ML, et al. Respiratory infections in infants: interaction of parental allergy, child care, and siblingsthe PIAMA study. Pediatrics. 2001;108:943-948. doi:10.1542/ peds. 108.4.943

123. Candy DCA, Van Ampting MT, Nijhuis MMO, et al. A synbiotic-containing amino-acid-based formula improves gut microbiota in non-IgE-mediated allergic infants. Pediatric Res. 2018;83:677-686. doi:10.1038/pr.2017.270

124. Fox AT, Wopereis H, Van Ampting MTJ, et al. A specific synbiotic-containing amino acid-based formula in dietary management of cow's milk allergy: a randomized controlled trial. Clin Transl Allergy. 2019;9:5. doi:10.1186/s13601-019-0267-6

125. Fox A, Bird JA, Fiocchi A, et al. The potential for pre-, pro- and synbiotics in the management of infants at risk of cow's milk allergy or with cow's milk allergy: an exploration of the rationale, available evidence and remaining questions. World Allergy Organ J. 2019;12:100034. doi:10.1016/j.waojou.2019.100034 
126. Sabouraud M, Biermé P, Andre-Gomez SA, et al. Oral immunotherapy in food allergies: a practical update for pediatricians. Arch Pediatr. 2021;28:319-324. doi:10.1016/j.arcped.2021.03.006

127. Boné Calvo J, Clavero Adell M, Guallar Abadía I, et al. As soon as possible in IgE-cow's milk allergy immunotherapy. Eur J Pediatr. 2021;180:291-294. doi:10.1007/s00431-020-03731

128. Berti I, Badina L, Cozzi G, et al. Early oral immunotherapy in infants with cow's milk protein allergy. Pediatr Allergy Immunol. 2019;30:572-574. doi:10.1111/pai.13057

129. Esmaeilzadeh H, Alyasin S, Haghighat M, Nabavizadeh $H$, Esmaeilzadeh E, Mosavat F. The effect of baked milk on accelerating unheated cow's milk tolerance: a control randomized clinical trial. Pediatr Allergy Immunol. 2018;29:747-753. doi:10.1111/pai.12958

130. Vilar LK, Araújo FA, Santos TP, Menezes TT, Cheik MF, Segundo GRS. Baked Tolerance in Cow's Milk Allergy: quite Frequent, Hard to Predict! Int Arch Allergy Immunol. 2021;182:319-323. doi:10.1159/000511148
131. Monaco S, Russo G, Romano A, Liotti L, Verga MC, Miceli Sopo S. Yogurt is tolerated by the majority of children with IgEmediated cow's milk allergy. Allergol Immunopathol. 2019;47:322-327. doi:10.1016/j.aller.2018.10.005

132. Cianferoni A. Eosinophilic Esophagitis as a side effect of food oral immunotherapy. Medicina. 2020;56:618. doi:10.3390/ medicina56110618

133. Gómez Torrijos E, Mendez Díaz Y, Moreno Lozano L, et al. Frequency and course of eosinophilic esophagitis during oral immunotherapy for cow's milk allergy in a series of 57 children. $J$ Investig Allergol Clin Immunol. 2017;27:132-133. doi:10.18176/jiaci.0130

\section{Publish your work in this journal}

The Journal of Asthma and Allergy is an international, peer-reviewed open-access journal publishing original research, reports, editorials and commentaries on the following topics: Asthma; Pulmonary physiology; Asthma related clinical health; Clinical immunology and the immunological basis of disease; Pharmacological interventions and new therapies. The manuscript management system is completely online and includes a very quick and fair peer-review system, which is all easy to use. Visit http://www.dovepress.com/testimonials.php to read real quotes from published authors. 